\title{
Twin pregnancies: a retrospective analysis
}

\author{
Tushar S. Zanjade, Madhurya Bezbaruah, Seema Rai, Jitendra D. Mane*
}

Department of Obstetrics and Gynaecology, Command Hospital (Southern Commanad), Wanowarie, Pune, Maharashtra, India

Received: 06 April 2021

Accepted: 19 April 2021

\section{*Correspondence:}

Dr. Jitendra D. Mane,

E-mail: Jitendra.mane@yahoo.com

Copyright: () the author(s), publisher and licensee Medip Academy. This is an open-access article distributed under the terms of the Creative Commons Attribution Non-Commercial License, which permits unrestricted non-commercial use, distribution, and reproduction in any medium, provided the original work is properly cited.

\begin{abstract}
Background: This study aims to analyse the maternal and neonatal complications in twin pregnancy at tertiary institute. Methods: This was a retrospective study of multiple pregnancies after 26 weeks gestation at a tertiary teaching hospital between January 2020 to December 2020. Maternal and neonatal data was collected from the labour room delivery register and NICU records.

Results: Out of 1212 births during this period, 66 were twin pregnancies with an incidence of 5.54\%. Most of women had twinning after in vitro fertilisation (IVF) treatment (77.27\%). Thirty-seven $(56.06 \%)$ women were in the age group of 21-30 years and primigravida contributed to $63.63 \%$ of all twin pregnancies. Maternal complications most frequently noticed was hypertensive disorders of pregnancy in 27 (40.90\%) women, Gestational diabetes mellitus (GDM) in 24 $(36.36 \%)$ women, preterm rupture of membranes (PROM)/ preterm premature rupture of membranes (PPROM) in 21 $(31.18 \%)$ women, Intrahepatic cholestasis of pregnancy (IHCP) in 4 (6.06\%) women, hypothyroidism in $12(18.8 .1 \%)$ women and antepartum hemorrhage (APH) in 4 (6.06\%). Caesarean section was performed on 49 (74.25\%) women with abnormal presentation as indication in $18(36.73 \%) .80 .30 \%$ women had preterm delivery with $86(65.15 \%)$ neonates having NICU admission. There was no maternal mortality and $1(1,16 \%)$ perinatal mortality in NICU admitted neonates.

Conclusions: This study reveals with increasing ART treatment the incidence of twin pregnancies is increasing along with its maternal complications like hypertensive disorders of pregnancy, GDM and preterm delivery. Frequent antenatal care for early detection of complications, multi-disciplinary approach is key for favourable outcome.
\end{abstract}

Keywords: Multiple pregnancies, ART, Hypertensive disorders of pregnancy, Preterm labour, Prematurity

\section{INTRODUCTION}

Higher order pregnancies are emerging as an important reason for increasing in surveillance during antenatal and intranatal period. The number of multiple pregnancies is increasing leading to frequent hospital visits and financial burden on the family. Such ladies need to get frequent and prolong admission during antenatal and postnatal period for management of different complications like as preeclampsia, antepartum and post-partum haemorrhage, anaemia, polyhydramnios, increased rate of caesarean section and preterm birth as compared to singleton pregnancies. ${ }^{1,2}$ Hence contributing to increased maternal and perinatal morbidity and mortality then singleton pregnancy. ${ }^{3,4}$

The prevalence of twin births varies from approximately 2-20/1000 births. Spontaneous higher order multiple conceptions are uncommon. The reported incidence ranges from $0.01 \%$ to $0.07 \%$ of all pregnancies. ${ }^{5}$

The incidence of twin gestations is increased considerably following increased use of assisted reproductive technology (ART) for conception due to increased 
incidence of infertility, delayed planning of pregnancy for stability and career. Overall complications occur in approximately $83 \%$ of twin pregnancies as compared to $25 \%$ in singleton pregnancies. For favourable obstetric and neonatal outcome more vigilance is needed.

The aim of the study was to analyse feto-maternal complications in multiple pregnancies.

\section{METHODS}

This retrospective observational study was conducted in the department of obstetrics and gynaecology in a tertiary care hospital. Labour room and NICU records for a period of one year between January 2020 to December 2020 were analysed.

Women with twin pregnancy admitted after period of viability i.e 26 weeks and beyond and delivered in our hospital during the study period were included in the study. Twins requiring admissions in neonatal units were also studied.

Details of patients like age, parity, gestational age, mode of conception and obstetric complications like hypertensive disorder of pregnancy, preterm labour, fetal growth restriction, PROM/PPROM, GDM were studied.

Mode of delivery for each patient recorded whether vaginal, those requiring instrumentation and also those who required caesarean section. Foetal outcome, gestational age at birth, weight at birth, and requirement for NICU admission was analyzed.

The statistical data was then analysed using SPSS 20. Variables studied were reported as the mean, range and standard deviation (SD).

Ethical committee clearance was not taken in view of retrospective study.

\section{RESULTS}

A total 1212 women delivered during the study period out which 66 were twin pregnancies i.e 54.5/1000 birth.

Mean maternal age was $29.45 \pm 4.01$ years of which primigravida women were forty-two $(63,63 \%)$ while multigravida were twenty four $(36.36 \%)$ women. Only thirteen $(19.69 \%)$ women delivered after 37 weeks with mean gestation being $34.53 \pm 2.56$ weeks. Table 1

Fifty-one (77.27\%) women conceived by IVF. A hypertensive disorder of pregnancies were the commonest complication in twenty seven $(40.90 \%)$ women followed by gestational diabetes mellitus (GDM) in twenty four (36.36\%). Other complications were PPROM/ PROM (31.81\%), Hypothyroidism (18.18\%), Intrahepatic cholestasis of pregnancy (IHCP) $(6.06 \%)$ and APH (6.06\%). (Table 2, 3)

Caesarean section was performed on forty-nine $(74.25 \%)$ women. Table 4. Abnormal presentation was indication in eighteen (36.73) women for caesarean section followed by fetal distress $(20.40 \%)$, non-progress of labour (12.24\%), failed induction $(10.20 \%)$, APH $(8.16 \%)$, severe preeclampsia (12.24 5) and Monoamniotic monochorionic twins $(2.04 \%)$. (Table 5)

Mean birth weight of twin I was $2.11 \pm 0.54 \mathrm{kgs}$ while of twin II was $2.02 \pm 0.49 \mathrm{kgs}$. Maximum neonates weigh between $1.5 \mathrm{kgs}$ to $2.5 \mathrm{kgs}$. Eighty-six (65.15\%) neonates were admitted in NICU for different indications. Of the $65.15 \%$ prematurity $(83.72 \%)$ being commonest followed by Respiratory distress syndrome (RDS) $26 \%$, FGR $3.03 \%$ and birth asphyxia $1.57 \%$. Two women had single intrauterine demise. One $(1.16 \%)$ neonatal died in NICU with multiple complications. (Table 6)

Table 1: Characteristic of patients.

\begin{tabular}{|c|c|c|c|c|}
\hline Characteristic & Number $(\mathbf{N}=66)$ & Percentage & Mean & SD \\
\hline Mean age $($ mean \pm SD) & - & - & 29.45 & \pm 4.01 \\
\hline \multicolumn{5}{|l|}{ Age } \\
\hline $20-\leq 29$ & 37 & 56.06 & & \\
\hline $30-\leq 34$ & 22 & 33.33 & & \\
\hline 35 years and beyond & 7 & 10.60 & & \\
\hline Primigravida & 42 & 63.63 & & \\
\hline Multigravida & 24 & 36.36 & & \\
\hline Mean gestational age $($ mean \pm SD) & - & - & 34.53 & \pm 2.56 \\
\hline$\leq 29+6$ weeks & 3 & 4.5 & & \\
\hline $30-\leq 33+6$ weeks & 17 & 25.75 & & \\
\hline $34-\leq 36+6$ weeks & 33 & 50 & & \\
\hline Beyond 37 weeks & 13 & 19.69 & & \\
\hline
\end{tabular}


Table 2: Mode of conception.

\begin{tabular}{|lll|}
\hline Mode & $\begin{array}{l}\text { Number } \\
(\mathbf{N}=66)\end{array}$ & Percentage \\
\hline Spontaneous & 06 & 9.09 \\
\hline IUI & 09 & 13.63 \\
\hline IVF & 51 & 77.27 \\
\hline
\end{tabular}

Table 3: Complications associated with twin pregnancies.

\begin{tabular}{|lll|}
\hline Complications & $\begin{array}{l}\text { Number } \\
(\mathbf{N}=66)\end{array}$ & Percentage \\
\hline $\begin{array}{l}\text { Hypertensive disorders } \\
\text { of pregnancy }\end{array}$ & 27 & 40.90 \\
\hline GDM & 24 & 36.36 \\
\hline PPROM/PROM & 21 & 31.81 \\
\hline Hypothyroidism & 12 & 18.18 \\
\hline IHCP & 04 & 6.06 \\
\hline APH & 04 & 6.06 \\
\hline
\end{tabular}

Table 4: Mode of delivery.

\begin{tabular}{|lll|} 
Mode of delivery & $\begin{array}{l}\text { Number } \\
(\mathbf{N}=66)\end{array}$ & Percentage \\
\hline Caesarean & 49 & 74.25 \\
\hline Vaginal & 17 & 25.75 \\
\hline
\end{tabular}

Table 5: Indication of caesarean section.

\begin{tabular}{|l|l|l|}
\hline Indications & $\begin{array}{l}\text { Number } \\
(\mathbf{N}=49)\end{array}$ & Percentage \\
\hline Abnormal presentation & 18 & 36.73 \\
\hline Fetal distress & 10 & 20.40 \\
\hline Non progress of labour & 6 & 12.24 \\
\hline Failed induction & 5 & 10.20 \\
\hline $\begin{array}{l}\text { APH (Abruptio/placenta } \\
\text { previa) }\end{array}$ & 4 & 8.16 \\
\hline $\begin{array}{l}\text { Severe preeclampsia } \\
\text { with unfavourable cervix }\end{array}$ & 6 & 12.24 \\
\hline MAMC Twin & 1 & 2.04 \\
\hline
\end{tabular}

Table 6: Neonatal outcome.

\begin{tabular}{|lllll|}
\hline Twin I & Number & $\%$ & Mean & SD \\
\hline Twin II & & & 2.11 & \pm 0.54 \\
\hline Weight & & & 2.02 & \pm 0.49 \\
\hline$<1.5 \mathrm{~kg}$ & 9 & 13.63 & & \\
\hline $1.5-<2 \mathrm{kgs}$ & 44 & 33.33 & & \\
\hline $2-<2.5 \mathrm{kgs}$ & 42 & 31.84 & & \\
\hline $\begin{array}{l}2.5 \mathrm{kgs} \text { and } \\
\text { beyond }\end{array}$ & 28 & 21.21 & & \\
\hline NICU admission & 86 & 65.15 & & \\
\hline
\end{tabular}

\section{DISCUSSION}

Of all the high-risk pregnancies twin pregnancies is emerging as an important factor requiring special care during antenatal and postnatal period. The incidence of twin gestation is increasing, our study population had incidence of $5.44 \%$.

Twinning was most frequently following in vitro fertilisation (IVF) $77.27 \%$ in our study this may be due assisted reproductive technique (ART) centre located in hospital and infertility couples are referred from peripheral hospital for treatment.

Even though twinning is on rise with ART treatment the mean age of the women was 29.45 years. Maximum age group with twin pregnancy was between 20 - 29 years $(56.06 \%)$ in our study whereas $86.9 \%$ and $81 \%$ in Dubey et al and Tomar et al respectively. ${ }^{6,7}$ This shows that maximum women who sought ART treatment are below 30 years.

$66.63 \%$ ladies were primigravida and $36.36 \%$ multigravida which was contrary to Spellacy et al in which $84.2 \%$ were multigravida. Dubey et al had $45.7 \%$ primigravida and $54.3 \%$ multigravida. ${ }^{6,8}$ Mean gestational age at delivery in our study was 34.53 weeks which was comparable with Erdemoghu et al and Yuel et al. ${ }^{9,10}$

Hypertensive disorder in pregnancy $(40.90 \%)$ was the most frequent complication associated with twin pregnancy in our study. 24 to $30 \%$ was noticed by other workers. ${ }^{11,12}$ PROM/PPROM was detected in twenty one $(31.81 \%)$ women which was similar to Chowdery et al $(38 \%) .{ }^{13}$ Very high number of women i.e $36.36 \%$ were found to have GDM while Dubey et al had $1.8 \%$ and Buhling et al reported $3.4 \%$ of patients and did not found any association with twin pregnancy. ${ }^{6,14}$ IHCP was observed in $6.06 \%$ women which was also noticed by Dubey et al in $5.5 \%$ women. $^{6}$

Seventeen $(25.75 \%)$ women had vaginal delivery while fourty nine $(74.25 \%)$ had caesarean section due to associate complications like hypertensive disorders of pregnancy, PPROM and IHCP and GDM. Assuncao et al has reported caesarean section in $84.8 \%$ whereas Deepthi et and Shetty et al reported $45 \%$ and $68 \%$ respectively. ${ }^{15,16}$ Commonest indication for caesarean section was abnormal presentation $(36.73 \%$ ) which was also seen by Bhalla et al $(48.14 \%)$ and Erdenoghu et al $(46.3 \%) .{ }^{9,11}$

$80.30 \%$ women had preterm delivery (spontaneous or induced) while $70 \%$ and $67 \%$ was found by other authers. ${ }^{6,11,17}$ Some researcher had lower incidence of preterm twin delivery i.e $50.7 \%$ and $41.5 \% .^{18,19}$ This high incidence is due to mostly IVF pregnancies with comorbidities requiring induction and PPROM.

NICU admissions was seen in $65.15 \%$ neonates which was similar to Bhalla et al i.e $66 \% .^{11} 78.8 \%$ neonates were weighing less than $2.5 \mathrm{kgs}$ in our study while Bengal et al study had $82 \% .{ }^{20}$ Prematurity was seen in $61(70.93 \%)$ neonates, RDS in $28(32.55 \%)$ neonates, fetal growth restriction in $6(6.97 \%)$, and birth asphyxia in $2(2.32 \%)$ 
neonates. In spite of high NICU admissions perinatal mortality was very low i.e $01(1,16 \%)$ compare to Ambiben et al of $26.5 \%$ this may be due to round the clock availability of experienced neonatologist and set NICU protocols. $^{20}$

\section{CONCLUSION}

Twin pregnancies is an important emerging high risk factor which warrants early detection, systematic evaluation and follow-up for identifications of complications and its management by multidisciplinary team for optimum outcome

\section{Funding: No funding sources}

Conflict of interest: None declared

Ethical approval: The study was approved by the Institutional Ethics Committee

\section{REFERENCES}

1. Smits J, Monden C. Twinning across the developing world. PLoS One. 2011;6(9):e25239.

2. Obiechina N, Okolie V, Eleje G. Twin versus singleton pregnancies: the incidence, pregnancy complications, and obstetric outcomes in a Nigerian tertiary hospital. Int J Womens Health. 2011;3:227.

3. Conde-Agudelo A, Belizan JM, Lindmark G. Maternal morbidity and mortality associated with multiple gestation. Obstet Gynecol. 2000;95:899-904.

4. Yasmeen N, Aleem M, Iqbal N. Maternal and fetal complications in multiple pregnancies. Ann K Ed Med Coll. 2006;12:512-4.

5. Umeora OUJ, AneziOkoro EA, Egwuatu VE. Higherorder multiple births in Abakaliki, Southeast Nigeria. Singapore. Med J. 2011;52(3):163-7.

6. Dubey S, Mehra R, Goel P, Rani J, Satodiya M. Maternal complications in twin pregnancy; recent trends: a study at a tertiary care referral institute in Northern India. Int J Reprod Contracept Obstet Gynecol 2018;7:3753-7.

7. Tomar SP, Kushwah SS, Kushwah AP. Association of sociodemographic factors with multiple births and birth outcomes in comparison to single births among deliveries conducted at a tertiary hospital in Rewa, Madhya Pradesh. Int J Students' Res. 2014;4(1):8.

8. Spellacy WN, Handler A, Ferre CD. A case control study of 1253 twin pregnancies from 1982-1987. Perinatal Data Base. 1990;75:198-71.
9. Erdemoglu M, Kale A, Akdeniz N, Yalinkaya A, Ozcan Y. Retrospective analysis of multiple pregnancies. Perinatal Journal. 2005;13(4).

10. Irene $\mathrm{YV}$, Vaneet K. An analytical study of pregnancy outcome in multifetal gestation. J Obstet Gynecol India. 2007;57(6):509-12.

11. Bhalla S, Bhatti SG, Devgan S. Obstetric and perinatal outcome of twin pregnancy: a prospective study in a tertiary care hospital in North India. Int J Reprod Contracept Obstet Gynecol 2018;7:2455-61.

12. Gajera AV, Basavannayya HP, Kavitha C, Hiremath R. Feto-maternal outcome in twin pregnancy. Int $\mathbf{J}$ Reprod Contracept Obstet Gynecol 2015;4:1836-9.

13. Chowdhury S. Clinical Study on twin pregnancy, FCPS. Bangladesh College of Physicians and Surgeons, Dhaka. 1998.

14. Buhling KJ, Henrich W, Starr E, Lubke M, Bertram $\mathrm{S}$, Siebert $\mathrm{G}$ et al. Risk for gestational diabetes and hypertension for women with twin pregnancy compared to singleton pregnancy. Arch of Gynecol Obstetr. 2003;269(1):33-6.

15. Deepthi HR, Pradeep MR, Lalitha S. Retrospective study of maternal and perinatal outcome of twin pregnancy in a teaching hospital. J Dental Med Sci. 2015;14(1):29-32.

16. Shetty MB, Shivananjaiah C, Swarup A. A retrospective study: twin gestation at tertiary care, maternal and fetal outcome. Int J Reprod Contracept Obstetr Gynecol. 2016;5(1):217-9.

17. Nandmer GK, Kanhere AV. Study of obstetric and fetal outcome of twin pregnancy in a tertiary care centre. Int J Reprod Contracept Obstetr Gynecol. 2017;4(6):1789-92.

18. Sultana H. Fetal and maternal outcome of twin pregnancy-A study of 50 cases. Bangladesh college of Physicians and Surgeons, Dhaka. 1998.

19. Chowdhury S, Hussain MA. Maternal complications in twin pregnancies. Mymensingh Med J. 2011;20(1):83-7.

20. Bangal VB, Patel SM, Khairnar DN. Study of maternal and fetal outcome in twin gestation at tertiary care teaching hospital. IJBAR. 2012;03(10):758-61.

Cite this article as: Zanjade TS, Bezbaruah M, Rai $\mathrm{S}$, Mane JD. Twin pregnancies: a retrospective analysis. Int J Reprod Contracept Obstet Gynecol 2021;10:1828-31. 